\title{
Surgical Implications of Asymmetric Distribution of Dermal Collagen and Elastic Fibres in Two Orientations of Skin Samples from Extremities
}

\author{
Naveen Kumar, ${ }^{1}$ Pramod Kumar, ${ }^{2}$ Satheesha Nayak Badagabettu, ${ }^{1}$ Keerthana Prasad, \\ Ranjini Kudva, ${ }^{4}$ and Raghuveer Coimbatore Vasudevarao ${ }^{5}$ \\ ${ }^{1}$ Department of Anatomy, Melaka Manipal Medical College, Manipal Campus, Manipal University, Manipal 576104, India \\ ${ }^{2}$ Department of Plastic Surgery, King Abdul Aziz Hospital, Sakaka, Al-Jouf 42421, Saudi Arabia \\ ${ }^{3}$ Department of Information Science, Manipal School of Information Science, Manipal University, Manipal 576104, India \\ ${ }^{4}$ Department of Pathology, Kasturba Medical College, Manipal University, Manipal 576104, India \\ ${ }^{5}$ Department of Pathology, Yenepoya University, Deralakatte, Mangalore 575018, India
}

Correspondence should be addressed to Pramod Kumar; kumar.drpramod@gmail.com

Received 20 August 2014; Accepted 28 November 2014; Published 23 December 2014

Academic Editor: Nicolo Scuderi

Copyright (C) 2014 Naveen Kumar et al. This is an open access article distributed under the Creative Commons Attribution License, which permits unrestricted use, distribution, and reproduction in any medium, provided the original work is properly cited.

\begin{abstract}
Background. Clinically, scar related complications are observed to be dissimilar in different regions of the body. Unequal distribution of dermal collagen and elastic fibres in different orientations could be one of the multifocal causes of scar related complications, for which this evaluating study has been taken up. Materials and Method. 300 skin samples collected in horizontal and vertical orientations were studied histomorphometrically. This study involved image analysis of specially stained histological section using tissue-quant software. The outcome result was termed as quantitative fraction. From the result, various ratio values were also calculated for the ratio analysis. Results. The differences in the quantitative fraction of dermal elastic content between 2 directions were statistically significant at joint areas (shoulder joint, wrist, and ankle) $(P<0.001)$ but for collagen, significant difference was observed at shoulder joint and wrist only. Dermis of the forearm and thigh did not show any differences in their collagen content, but for elastic, thigh did show a significant difference while forearm had no change between 2 directions. Conclusion. Analysis of unequal content of dermal element in two directions under the perspective of wound healing consequences is subjective depending upon the anatomical position and functional status of the areas.
\end{abstract}

\section{Introduction}

Collagen and elastic fibres are the two major dermal connective tissue populations that exhibit their functional significance during wound healing process. Various studies in this aspect have emphasized their complimentary functional attribution in the process of minimizing the scar formation [1]. The scar tissue resulting from the process of wound healing also has similar types of collagen as in normal skin but with a deviated pattern of arrangement and distribution from the normal [2].

For many years, the well-known direction followed to make incisions to obtain aesthetic scar has been Langer's line or cleavage line. There have been many other concepts of lines on the skin which have been put forward and made the concept of Langer's line debatable. Borges studied intensely the lines of skin tension and comprehended with seven best known skin tension lines. According to him, single best choice of line is still questionable to fulfill complete satisfaction of wound healing [3]. Most popular among these is the Langer's line, concept of which lies on the basis of pattern of arrangement of dermal collagen in a particular direction. Previous works on the quantification of dermal collagen and elastic fibres in two different directions of skin samples obtained from the same area of the human body did confirm the asymmetric distribution of them $[1,4,5]$. The results of these studies attempted a hypothetical explanation 
which possibly explains pleomorphic behaviour of scar in different parts of the body.

Plastic surgeons on the other hand, in their personal experience and observations in the clinical setup, are still in dilemma about the speckled behaviour of scar, even after the incisions are made on the skin according to the standard lines of choice. This made them theorize the possible role of varied quantity and content of dermal collagen together with elastic fibres in different orientations of skin plane in addition to their normal coalition pattern in the dermis. For research purpose, quantification of dermal connective tissue fibres using image analysis technique was reported to be more relevant than the observer's ratings as it is accurate and comparable to polarized light technique [6]. The percentage area occupied by the tissue structures demonstrated by biological stains can be measured by image analysis and its accuracy and reliability have been proved by previous studies $[1,4,5,7]$. Using similar methodology, histomorphometric analysis of dermal collagen and elastic fibres in two directions from the areas of head and neck [4] and trunk region [5] confirmed its asymmetric distribution as well as diverged content among themselves whose significance was in justification with the observation of life.

\section{Materials and Methods}

Current study involved 300 skin samples collected in two orientations (horizontal and vertical) from five areas (shoulder joint, wrist, ankle, forearm, and thigh) of extremity region of human cadaver. The skin samples were obtained from 30 formalin embalmed healthy looking human cadavers with the age of approximately $55 \pm 5$ years. All the samples were immediately immersed in $10 \%$ formalin followed by further histological processing. Elliptical skin samples were divided across their long axis before embedding them in the paraffin mould. In the mould, they were oriented in such a way that their cut edges were directed as cutting surfaces. Topographic sites where the skin samples were obtained are illustrated in Figure 1.

\subsection{Sample Collection}

(i) At shoulder joint, the skin samples were obtained slightly lateral to surface projection overlying the acromion process of scapula. Sections taken along the circumferential line of joint were considered as "horizontal," while perpendicular to it as "vertical."

(ii) Over the wrist area, skin samples in 2 directions were obtained at the side of proximal crease line of flexor surface.

(iii) At ankle area, skin samples were collected at the site immediately above the topographic site of insertion of tendocalcaneous.

(iv) Forearm skin samples were collected over the middle of flexor compartment of the forearm between midpoint of elbow joint and wrist joint.

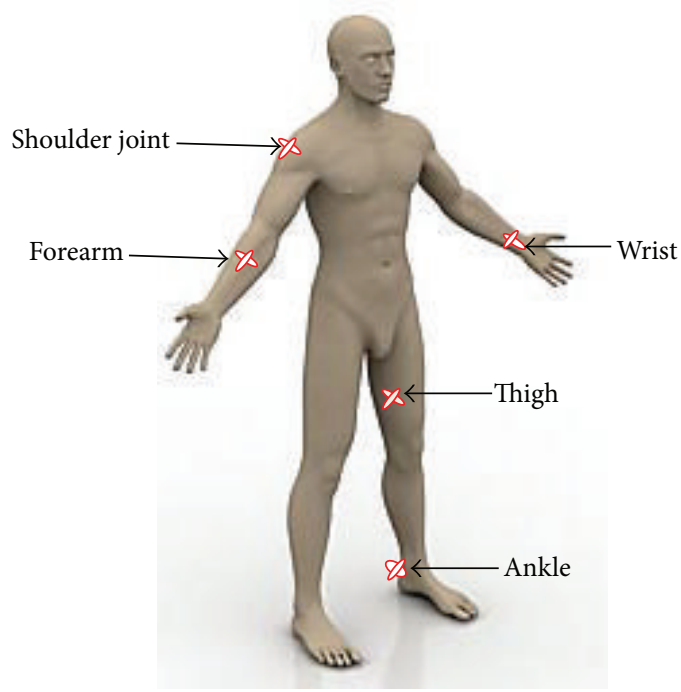

Figure 1: Topographic areas of sample collection from extremity region of human body (adapted from http://www.designyourway .net/blog/).

(v) At thigh region, samples were collected along the midpoint on thigh between pubic tubercle and medial condyle of tibia.

2.2. Histological Processing and Image Acquisition. Histological sections were stained by special stain Verhoeff-Van Gieson method for the selective demonstration of collagen and elastic fibres [8]. Digital images were acquired at 20x magnification with the standard resolution of $694 \times 516$ VGA using Progress capture Pro 2.1-Jenoptic microscopic camera fitted to inverted phase contrast camera. From each sample three images were obtained in 3 different microscopic fields.

2.3. Image Analysis. Images obtained from special stained slides were subjected to analysis by the software "tissuequant" version 1.0. This software measures the area occupied by the coloured structure of interest in terms of number of pixels assigned to positively stained area in the image. This measure corresponds to the quantitative fraction of the structure to be analysed. Tissue-quant analysis needs as prerequisites the segmentation of colour and its shades of interest from the rest of the coloured structures (Figure 2). The total number of pixels corresponding to the target area of coloured structure is then converted to percentage value by proper calculation [7].

\subsection{Analyzed Morphometric Parameters}

2.4.1. Quantitative Fraction Analysis. Image analysis results obtained in terms of percentage area occupied by the collagen and elastic fibres were termed as quantitative fraction. Mean value with standard deviation was calculated and the differences of variables between the samples of two orientations were analysed statistically by employing the paired sample $t$ test with 95\% confidence interval (CI) using SPSS version 5. $P<0.05$ is considered to be statistically significant. 

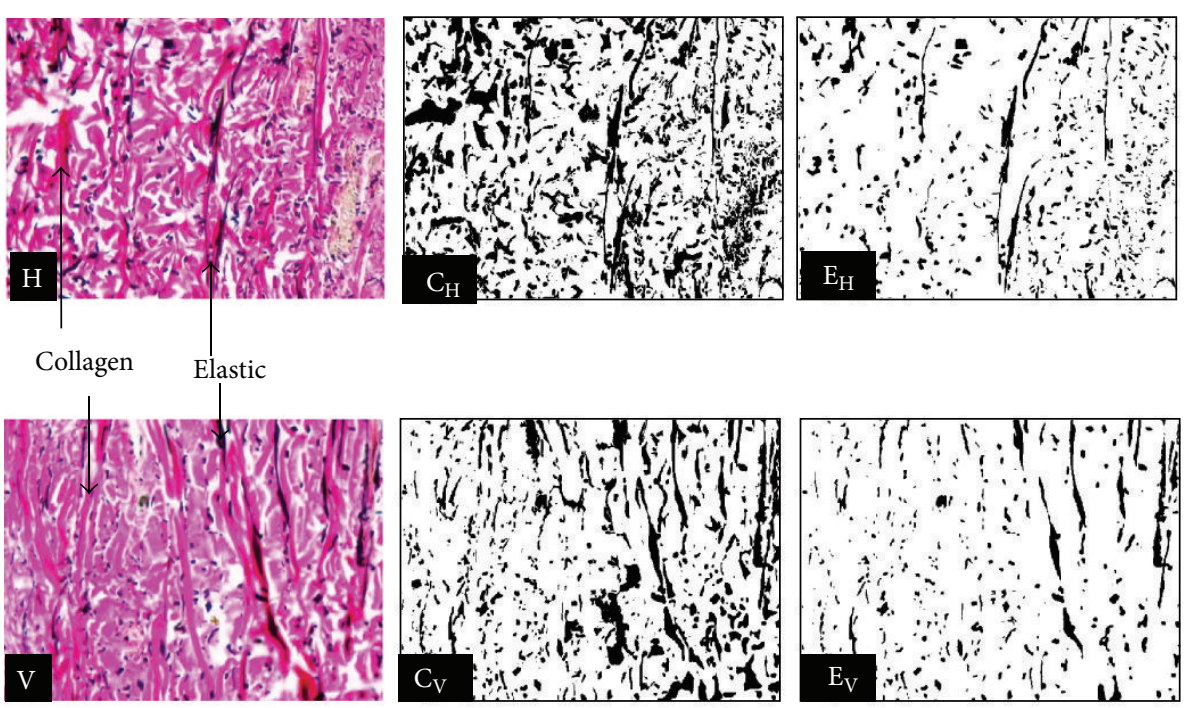

Shoulder joint
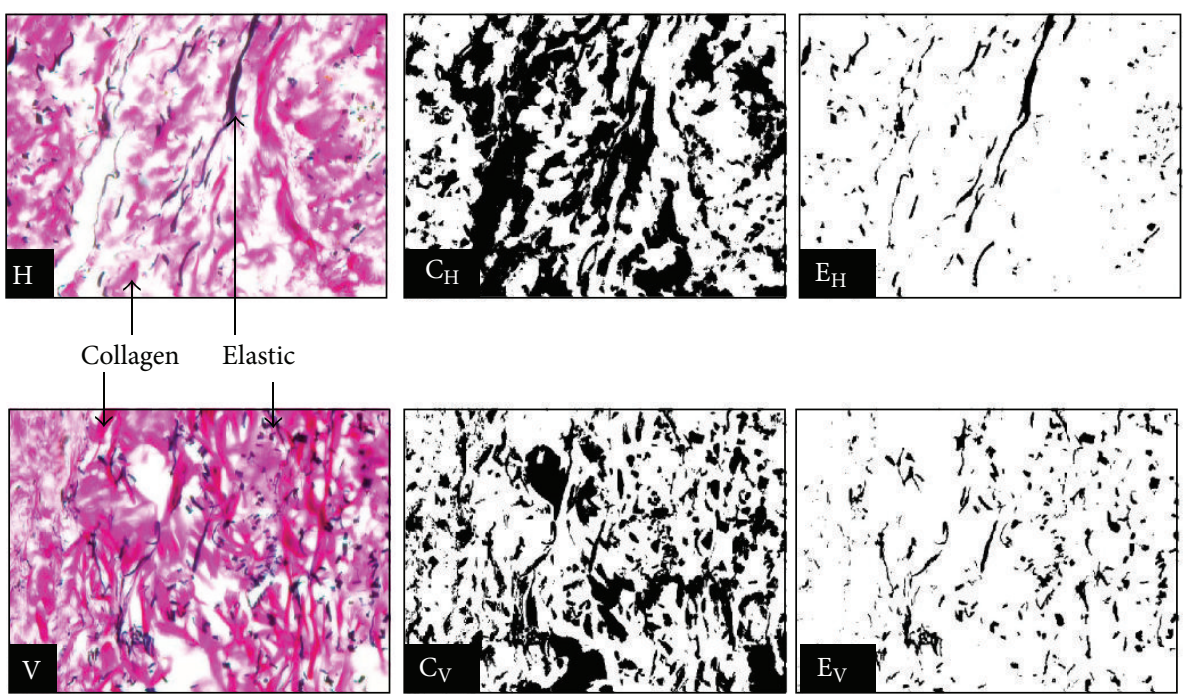

Wrist
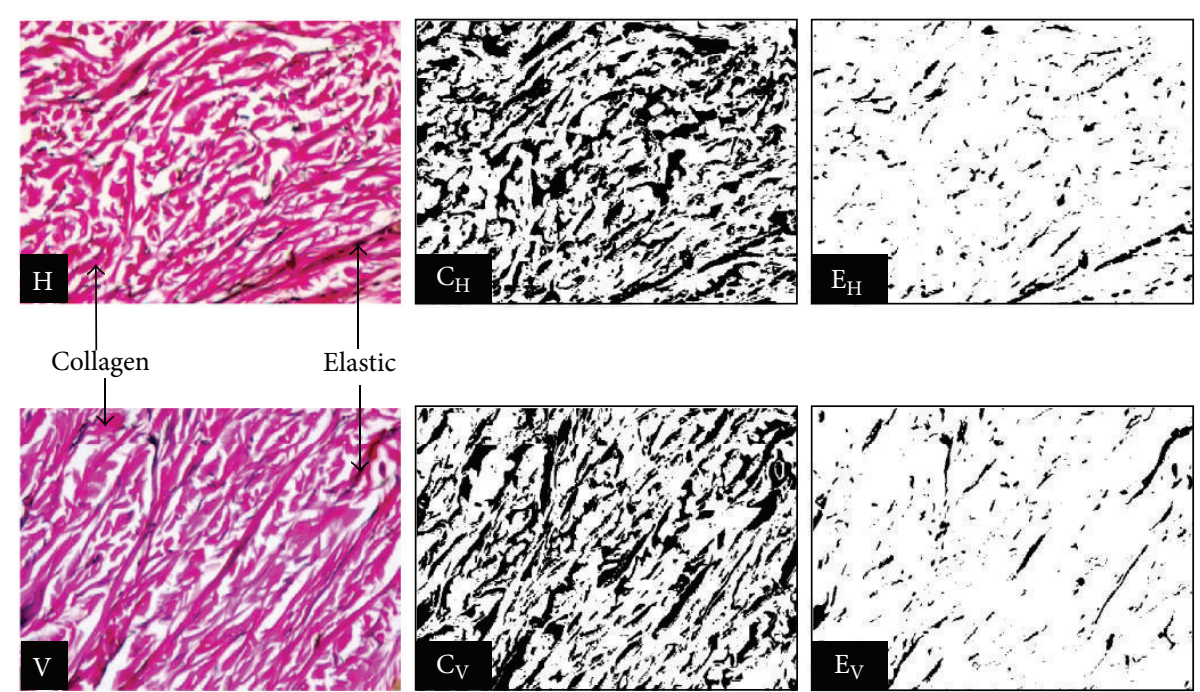

(a)

Figure 2: Continued. 

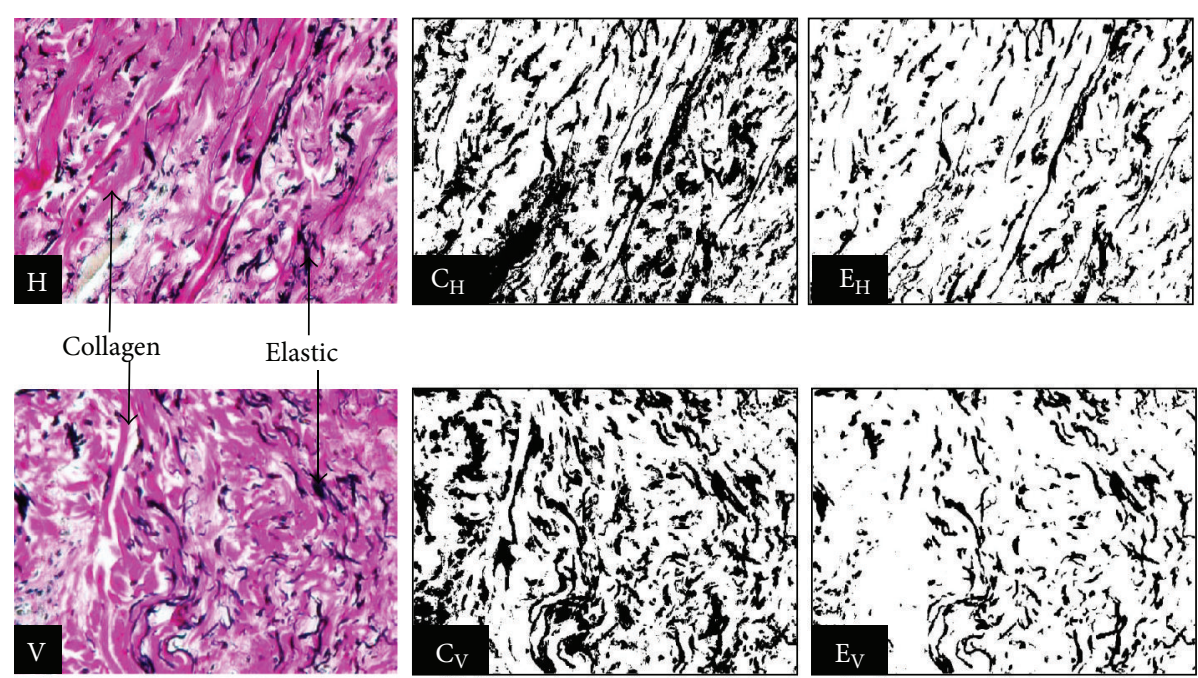

Forearm
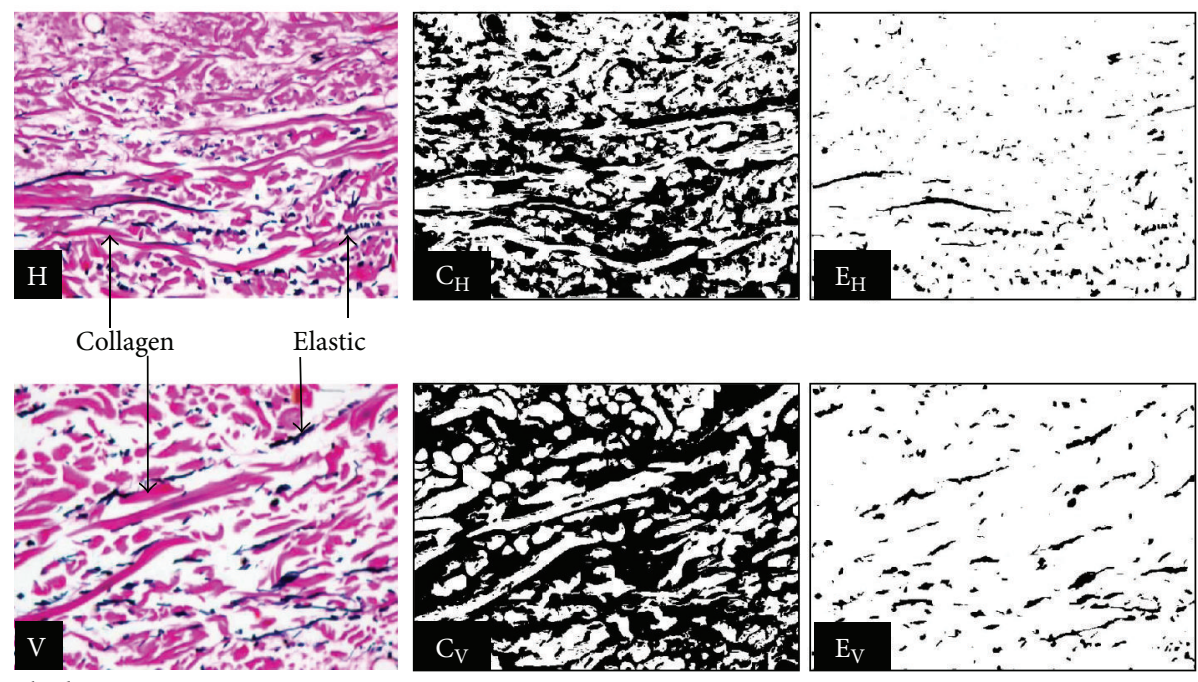

Thigh

(b)

FIGURE 2: Verhoeff-Van Gieson staining appearance of collagen (pink colour) and elastic fibres (black colour) in horizontal (H) and vertical (V) sections of shoulder joint, wrist, ankle, forearm, and thigh areas. Their pattern of segmentation by tissue-quant software is shown in adjacent photographs. [ $\mathrm{C}_{\mathrm{H}}$ : collagen in horizontal, $\mathrm{C}_{\mathrm{V}}$ : collagen in vertical, $\mathrm{E}_{\mathrm{H}}$ : elastic in horizontal, and $\mathrm{E}_{\mathrm{V}}$ : elastic in vertical directions].

2.4.2. Ratio Value Analysis. The collagen and elastic fibre content in horizontally obtained sections were denoted as $\mathrm{C}_{\mathrm{H}}$ and $\mathrm{E}_{\mathrm{H}}$, respectively, while for their vertical directions as $\mathrm{C}_{\mathrm{V}}$ and $\mathrm{E}_{\mathrm{V}}$, respectively. The ratio between $\mathrm{C}_{\mathrm{H}}$ and $\mathrm{C}_{\mathrm{V}}$ was calculated by dividing the $\mathrm{C}_{\mathrm{V}}$ value by $\mathrm{C}_{\mathrm{H}}$ and it was denoted by $\mathrm{C}_{\mathrm{V}} / \mathrm{C}_{\mathrm{H}}$ ratio. Similarly, the ratio between $\mathrm{E}_{\mathrm{H}}$ and $\mathrm{E}_{\mathrm{V}}$ was calculated by dividing the $\mathrm{E}_{\mathrm{V}}$ value by $\mathrm{E}_{\mathrm{H}}$ and it was denoted by $\mathrm{E}_{\mathrm{V}} / \mathrm{E}_{\mathrm{H}}$ ratio. These ratios were expressed in "ratio values" which implies proportionate changes in content of "vertical" with respect to its "horizontal" counterpart [1].

\section{Results}

3.1. Quantitative Fraction Analysis. The mean quantitative fraction with standard deviation (SD) and mean 95\% confidence interval $(\mathrm{CI})$ for collagen in horizontal $\left(\mathrm{C}_{\mathrm{H}}\right)$ and collagen in vertical direction $\left(\mathrm{C}_{\mathrm{V}}\right)$ with the level of statistical significance ( $P$ values) between two directions are depicted in Table 1.

The mean $\mathrm{C}_{\mathrm{H}}$ of dermis overlying shoulder joint was $53.91 \%$ and that of $C_{V}$ was $49.03 \%$ with a significant difference between two directions $(P=0.005)$. The $\mathrm{C}_{\mathrm{H}}$ in wrist area was $56.12 \%$ and that of its $\mathrm{C}_{\mathrm{V}}$ was $60.32 \%$. The wide difference between $\mathrm{C}_{\mathrm{H}}$ and $\mathrm{C}_{\mathrm{V}}$ confirmed the statistical significance with $P=0.016$. In the ankle, $\mathrm{C}_{\mathrm{H}}$ was $61.61 \%$ and $\mathrm{C}_{\mathrm{V}}=62.37 \%$. The difference in the ankle area was very narrow; thus it was statistically insignificant $(P=0.640)$. The $\mathrm{C}_{\mathrm{H}}$ and $\mathrm{C}_{\mathrm{V}}$ at forearm were similar to each other, that is, $52.84 \%$ and $52.56 \%$, respectively, without any notable difference $(P=0.856)$. Dermis of the thigh area, similar to forearm, also exhibited close ranges of collagen content between horizontal $\left(\mathrm{C}_{\mathrm{H}}=\right.$ $52.12 \%)$ and vertical $\left(\mathrm{C}_{\mathrm{V}}=52.06 \%\right)$ directions. The level 
TABLE 1: Descriptive statistics of collagen fibre assay between horizontal $\left(\mathrm{C}_{\mathrm{H}}\right)$ and vertical $\left(\mathrm{C}_{\mathrm{V}}\right)$ directions from the areas of extremity region of human cadaver.

\begin{tabular}{|c|c|c|c|c|}
\hline Area & $\begin{array}{c}\text { Horizontal }\left(\mathrm{C}_{\mathrm{H}}\right) \\
\text { Mean }(\mathrm{SD})\end{array}$ & $\begin{array}{c}\text { Vertical }\left(\mathrm{C}_{\mathrm{V}}\right) \\
\text { Mean }(\mathrm{SD})\end{array}$ & Mean 95\% CI & $P$ value \\
\hline Shoulder joint & $53.91(12.3)$ & $49.03(10.6)$ & 4.88 & $0.005^{*}$ \\
\hline Wrist & $56.12(12.0)$ & $60.32(11.2)$ & -4.19 & $0.016^{*}$ \\
\hline Ankle & $61.61(7.7)$ & $62.37(8.1)$ & -0.75 & 0.640 \\
\hline Forearm & $52.84(12.2)$ & $52.56(12.1)$ & 0.28 & 0.856 \\
\hline Thigh & $52.12(12.3)$ & $52.06(14.1)$ & 0.06 & 0.964 \\
\hline
\end{tabular}

${ }^{*}$ Indicates statistically significant difference of content between horizontal and vertical direction $(P<0.05)$.

of significance in the difference was statistically insignificant $(P=0.964)$.

The mean quantitative fraction with standard deviation (SD) and mean $95 \%$ confidence interval (CI) for elastic fibre content between horizontal $\left(\mathrm{E}_{\mathrm{H}}\right)$ and vertical $\left(\mathrm{E}_{\mathrm{V}}\right)$ directions with its level of statistical significance of differences ( $P$ values) are depicted in Table 2.

The content of elastic fibres in skin of shoulder joint was $10.34 \%$ and $13.07 \%$ for $\mathrm{E}_{\mathrm{H}}$ and $\mathrm{E}_{\mathrm{V}}$, respectively. The difference was statistically significant $(P=0.011)$. In the wrist, $\mathrm{E}_{\mathrm{H}}$ was $6.36 \%$ and it was much lesser than its $\mathrm{E}_{\mathrm{V}}(8.20 \%)$ making remarkable difference which was statistically significant $(P=$ $0.014)$. In the ankle, $\mathrm{E}_{\mathrm{H}}$ was $5.06 \%$ and $\mathrm{E}_{\mathrm{V}}$ was $8.14 \%$ with the statistical significance $(P=0.001)$. Similar to collagen at forearm, the elastic content was also more or less the same, as $\mathrm{E}_{\mathrm{H}}$ was $14.38 \%$ and $\mathrm{E}_{\mathrm{V}}$ was $14.28 \%(P=0.892)$. Unlike the collagen, in the thigh, the amount of elastic showed the significant difference in its content $(P=0.028)$ between horizontal $\left(\mathrm{E}_{\mathrm{H}}=14.68 \%\right)$ and vertical $\left(\mathrm{E}_{\mathrm{V}}=12.32 \%\right)$ directions.

3.2. Ratio Value Analysis. Results of various ratio values of collagen and elastic fibres between horizontal and vertical directions are tabulated in Table 3. For description purpose, the ratio values obtained from statistically significant $(P<$ $0.05)$ quantitative fractions were considered.

\section{Discussion}

A quantitative study of dermal collagen using computerized digital image analysis with comparison of its biochemical analysis was reported to be significantly correlated. The reason for this observation was attributed to the pattern of distribution of collagen irrespective of its type in the dermis [9]. In the human body, the collagen fibres display basket weave like pattern with the random organization [10]. Although the collagen fibre density evaluation normally does not show changes with age, decrease in its content was reported with the observation in individual variations [9]. Even the elastic fibre distribution assay in this aspect was also found to have no variation with respect to sex or age [11].

Stereological analysis of dermal collagen and elastic fibres done by Vitellaro-Zuccarello et al. reported constant volume of collagen throughout the depth of the dermis and increased density of the collagen as age advances in both sexes up to 30-40 years. On the other hand, the elastic fibre's volume and diameter vary in dermal layers and the increment is observed in reticular dermis particularly in males till first decade of life [12]. The elastin content differs and distribution is dependent on the dermal area as it is different among the subjects [13]. In response to stretch, both elastic and collagen fibre's realignment are observed [14].

Subcutaneous or fascial tensile reduction sutures tend to apply negligible tension that in turn plays an effective role in the reduction of recurrence of keloids or hypertrophic scars [15]. The quantitative fraction evaluation of dermal collagen and elastic fibres in the extremities of the body is highly intricate and subjective due to involvement of joints. The present study involves 3 joint areas (shoulder joint, wrist, and ankle) and two other nonstretchable areas (thigh and forearm). For joint area, the evaluation was made under two factors involving burst force exerted over the stretched skin of flexed/adducted joint (e.g., the shoulder joint) and stretch force over skin during movement at joints that are not acutely bent in rest position (e.g., wrist and ankle joint).

4.1. Shoulder Joint Area. During normal adducted position at rest, the maximum stretch on the shoulder skin over deltoid region causing burst force with the tendency to create wound in vertical direction. To counteract this force in nature, strength is required along horizontal direction. Thus, the collagen deposition (that provides strength) predominates along the horizontal direction. This was evident from our data in which significant higher collagen fibre content in horizontal direction compared to the vertical direction $\left(\mathrm{C}_{\mathrm{H}}=53.91 \%\right.$ versus $\mathrm{C}_{\mathrm{V}}=49.03 \%, P=0.005$ ) was seen. To compensate between excess stretching and laxity on one or another surface of joint during movement, elastic fibres necessitate increased concentration in vertical direction, that is, perpendicular to the joint line. This was confirmed with our findings in which elastic fibre content $\left(\mathrm{E}_{\mathrm{V}}=13.07 \%\right)$ was significantly higher than horizontal $\left(\mathrm{E}_{\mathrm{H}}=10.34 \%\right)$ direction $(P=0.011)$.

Thus, when the scar is placed in vertical direction over deltoid region, the burst force during adducted position tends to exhibit wide and/or hypertrophic scar in due course of time. On the other hand, when the scar is placed along horizontal direction, the elastic content in vertical direction is divided and exerts pull on the wound edge producing stretched and/or hypertrophied scar (gaping). Also, the effect of gravity aggravates the force on the horizontal wound edge exerted by divided elastic fibres. Since surgical incision is made along the horizontal direction, the tension produced by elastic fibres on wound/scar edge is probably weaker than 
TABLE 2: Descriptive statistics of elastic fibre assay between horizontal $\left(\mathrm{E}_{\mathrm{H}}\right)$ and vertical $\left(\mathrm{E}_{\mathrm{V}}\right)$ direction from the areas of extremity region of human cadaver.

\begin{tabular}{|c|c|c|c|c|}
\hline Area & $\begin{array}{c}\text { Horizontal }\left(\mathrm{E}_{\mathrm{H}}\right) \\
\text { Mean }(\mathrm{SD})\end{array}$ & $\begin{array}{c}\text { Vertical }\left(\mathrm{E}_{\mathrm{V}}\right) \\
\text { Mean }(\mathrm{SD})\end{array}$ & Mean 95\% CI & $P$ value \\
\hline Shoulder joint & $10.34(4.5)$ & $13.07(5.9)$ & -2.73 & $0.011^{*}$ \\
\hline Wrist & $6.36(2.6)$ & $8.20(3.5)$ & -1.84 & $0.014^{*}$ \\
\hline Ankle & $5.06(2.2)$ & $8.14(4.2)$ & -3.07 & $0.001^{*}$ \\
\hline Forearm & $14.38(4.7)$ & $14.28(6.4)$ & 0.10 & 0.892 \\
\hline Thigh & $14.68(6.7)$ & $12.32(5.4)$ & 2.36 & $0.028^{*}$ \\
\hline
\end{tabular}

${ }^{*}$ Indicates statistically significant difference in the content between horizontal and vertical direction $(P<0.05)$.

TABLE 3: Descriptive analysis of ratio values of collagen (C) and elastic (E) fibres with respect to horizontal $(\mathrm{H})$ and vertical $(\mathrm{V})$ directions.

\begin{tabular}{lcc}
\hline Areas & $\mathrm{C}_{\mathrm{V}} / \mathrm{C}_{\mathrm{H}}$ ratio value & $\mathrm{E}_{\mathrm{V}} / \mathrm{E}_{\mathrm{H}}$ ratio value \\
\hline Shoulder joint & $0.90^{\#}$ & $1.26^{\#}$ \\
Wrist & $1.07^{\#}$ & $1.28^{\#}$ \\
Ankle & 1.01 & $1.60^{\#}$ \\
Forearm & 0.99 & 0.99 \\
Thigh & 0.99 & $0.83^{\#}$ \\
\hline
\end{tabular}

${ }^{\#}$ Ratio values of statistically significant quantitative fraction $(P<0.05)$.

TABLE 4: Force effects at joint areas in anatomical position and during various movements.

\begin{tabular}{lccc}
\hline Force applicable & Shoulder joint & Wrist area & Ankle area \\
\hline $\begin{array}{l}\text { Burst force due to position } \\
\text { Stretch force due to }\end{array}$ & Maximum & Minimum & Moderate \\
movement & Minimum & Maximum & Moderate \\
\hline
\end{tabular}

burst force due to adducted position (rest position); resulting scar will be better if incision is horizontally placed compared to vertically.

4.2. Wrist and Ankle. Similar to shoulder joint area, the functional correlation of elastic fibres in vertical direction is comparable with that of shoulder joint area as the quantitative fraction of elastic fibre was significantly increased at vertical direction at wrist $\left(\mathrm{E}_{\mathrm{H}}=6.36\right.$ and $\mathrm{E}_{\mathrm{V}}=8.20$ with $\left.P=0.014\right)$ and at ankle $\left(\mathrm{E}_{\mathrm{H}}=5.06\right.$ and $\mathrm{E}_{\mathrm{V}}=8.14$ with $\left.P=0.001\right)$ areas.

However, in terms of collagen content, both wrist and ankle exhibit higher content of collagen in vertical direction which is contrary to shoulder joint area. But the difference was observed to be significant in wrist $\left(\mathrm{C}_{\mathrm{H}}\right.$ versus $\mathrm{C}_{\mathrm{V}}, P=$ $0.016)$ and insignificant at ankle $\left(\mathrm{C}_{\mathrm{H}}\right.$ versus $\left.\mathrm{C}_{\mathrm{V}}, P=0.640\right)$. This diverged fact of collagen content may be considered to be anatomical (rest) position of the joint which in turn could be attributed to the facts of burst force versus stretch force as shown in Table 4.

4.3. Forearm and Thigh Area. Since there is a minimal effect of movement and gravity over the thigh and forearm skin, no significant differences in the collagen and elastic fibre content between horizontal and vertical directions were to be expected. The results of current study partially support this hypothesis in terms of elastic content except that significant difference in the elastic fibre content over horizontal direction of the thigh region was noted. This becomes obligatory due to a possible stretch force produced by the slow circumferential tissue expansion of bulky thigh with growth of the body that necessitates deposition of more elastic along horizontal direction compared to vertical $\left(\mathrm{E}_{\mathrm{H}}>\mathrm{E}_{\mathrm{V}} ; P=0.028\right)$. Contrary to this, the circumferential growth of forearm is less as compared to that of thigh region; the above mentioned observation of thigh is unseen at forearm. As a result, there was no significant difference in elastic content of forearm between two directions $\left(\mathrm{E}_{\mathrm{H}}=14.38 \%, \mathrm{E}_{\mathrm{V}}=14.28 \%, P=0.892\right)$.

4.4. Ratio Value Evaluation (Table 3). In the shoulder joint area the $\mathrm{C}_{\mathrm{V}} / \mathrm{C}_{\mathrm{H}}$ ratio value was less than 1 . Horizontal wound edges on this area will often have less distracting force during movements as compared to the burst force on vertical wound edge during rest period. Clinical experience also shows that lower is the value and better is the long term result of horizontally placed scar.

In the wrist area, where the $C_{V} / C_{H}$ ratio value was more than 1 , burst force produced in horizontal direction during movements (mainly in extension) necessitates providing maximum strength to reduce damage. Due to this, probably collagen content in vertical direction was more.

In the thigh area, where the $\mathrm{E}_{\mathrm{V}} / \mathrm{E}_{\mathrm{H}}$ ratio value was less than 1 , the slow expansion of the tissues causes maximum stretch force in horizontal direction. Therefore elastic content was significantly higher in horizontal direction than in vertical.

In all 3 joint areas (shoulder joint, ankle, and wrist) with the $\mathrm{E}_{\mathrm{V}} / \mathrm{E}_{\mathrm{H}}$ ratio value more than 1, the constant stretching in vertical direction due to either embryologic growth pattern or gradual growth after birth might have influenced the higher content of elastic fibres along vertical directions (Table 2).

\section{Conclusion}

The analysis of unequal distribution of dermal collagen and elastic fibres in the region of extremities is a complex process and it is solely dependent on the anatomical perspective of the joints involved. The burst force and the stretch force effects at the joint area and corresponding profiles of quantitative fraction of dermal elements need to be taken into consideration before performing surgical incision. In other 
areas (forearm and thigh) these factors may have negligible effects.

\section{Conflict of Interests}

The authors declare that there is no conflict of interests regarding the publication of this paper.

\section{Authors' Contribution}

Naveen Kumar is responsible for integrity and accuracy of the data analysis, Pramod Kumar and Satheesha Nayak Badagabettu are responsible for study concept and design, Keerthana Prasad is responsible for data analysis, Raghuveer Coimbatore Vasudevarao and Ranjini Kudva are responsible for critical revision of the paper, and Pramod Kumar is responsible for study supervision.

\section{Acknowledgment}

Thanks are due to Ms. Mellisa Glenda Lewis (Research Scholar, Department of Statistics, Manipal University, Manipal) for the statistical analysis.

\section{References}

[1] K. Naveen, K. Pramod, P. Keerthana, and N. B. Satheesha, "A histological study on the distribution of derma l collagen and elastic fibres in different regions of the body," International Journal of Medicine and Medical Sciences, vol. 4, no. 8, pp. 171-176, 2012.

[2] J. A. Sherratt, Mathematical Modelling of Scar Tissue Formation, Department of Mathematics, Heriot-Watt University, Edinburgh, UK, 2010, http://www.ma.hw.ac.uk/ jas/researchinterests/scartissueformation.html.

[3] A. F. Borges, "Relaxed skin tension lines (RSTL) versus other skin lines," Plastic and Reconstructive Surgery, vol. 73, no. 1, pp. 144-150, 1984.

[4] K. Naveen, K. Pramod, P. Keerthana, N. B. Satheesha, K. Ranjini, and C. V. Raghuveer, "Histomorphometric analysis of dermal collagen and elastic fibres in skin tissues taken perpendicular to each other from head and neck region," Journal of the American Academy of Orthopaedic Surgeons, vol. 4, no. 1, pp. 30-36, 2014.

[5] N. Kumar, P. Kumar, S. N. Badagabettu, K. Prasad, R. Kudva, and C. V. Raghuveer, "Quantitative fraction evaluation of dermal collagen and elastic fibres in the skin samples obtained in two orientations from the trunk region," Dermatology Research and Practice, vol. 2014, Article ID 251254, 7 pages, 2014.

[6] P. P. M. van Zuijlen, H. J. C. de Vries, E. N. Lamme et al., "Morphometry of dermal collagen orientation by Fourier analysis is superior to multi-observer assessment," The Journal of Pathology, vol. 198, no. 3, pp. 284-291, 2002.

[7] K. Prasad, P. B. Kumar, M. Chakravarthy, and G. Prabhu, "Applications of "TissueQuant" - a color intensity quantification tool for medical research," Computer Methods and Programs in Biomedicine, vol. 106, no. 1, pp. 27-36, 2012.

[8] D. B. John, Theory and Practice of Histological Techniques, Marilyn Gamble, Churchil Livingstone, Philadelphia, Pa, USA, 5th edition, 2002.

[9] M. C. Branchet, S. Boisnic, C. Frances, C. Lesty, and L. Robert, "Morphometric analysis of dermal collagen fibers in normal human skin as a function of age," Archives of Gerontology and Geriatrics, vol. 13, no. 1, pp. 1-14, 1991.

[10] P. P. M. Van Zuijlen, J. J. B. Ruurda, H. A. Van Veen et al., "Collagen morphology in human skin and scar tissue: no adaptations in response to mechanical loading at joints," Burns, vol. 29, no. 5, pp. 423-431, 2003.

[11] C. Frances, M. C. Branchet, S. Boisnic, C. L. Lesty, and L. Robert, "Elastic fibers in normal human skin. Variation with age: a morphometric analysis," Archives of Gerontology and Geriatrics, vol. 10, no. 1, pp. 57-67, 1990.

[12] L. Vitellaro-Zuccarello, S. Cappelletti, V. dal Pozzo Rossi, and M. Sari-Gorla, "Stereological analysis of collagen and elastic fibers in the normal human dermis: variability with age, sex, and body region," Anatomical Record, vol. 238, no. 2, pp. 153-162, 1994.

[13] I. Pasquaili-Ronchetti and M. Baccarani-Contri, "Elastic fiber during development and aging," Microscopy Research and Technique, vol. 38, no. 4, pp. 428-435, 1997.

[14] P. D. Verhaegen, H. J. Schouten, W. Tigchelaar-Gutter et al., "Adaptation of the dermal collagen structure of human skin and scar tissue in response to stretch: an experimental study," Wound Repair and Regeneration, vol. 20, no. 5, pp. 658-666, 2012.

[15] R. Ogawa, S. Akaishi, C. Huang et al., "Clinical applications of basic research that shows reducing skin tension could prevent and treat abnormal scarring: the importance of fascial/ subcutaneous tensile reduction sutures and flap surgery for keloid and hypertrophic scar reconstruction," Journal of Nippon Medical School, vol. 78, no. 2, pp. 68-76, 2011. 


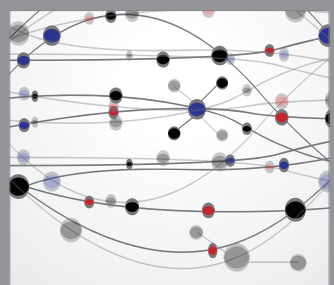

The Scientific World Journal
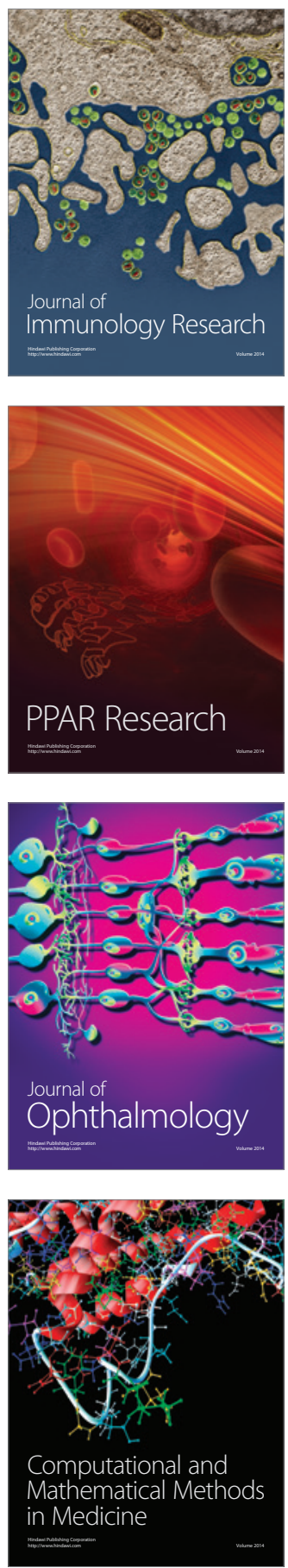

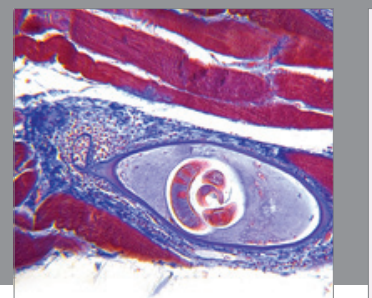

Gastroenterology

Research and Practice
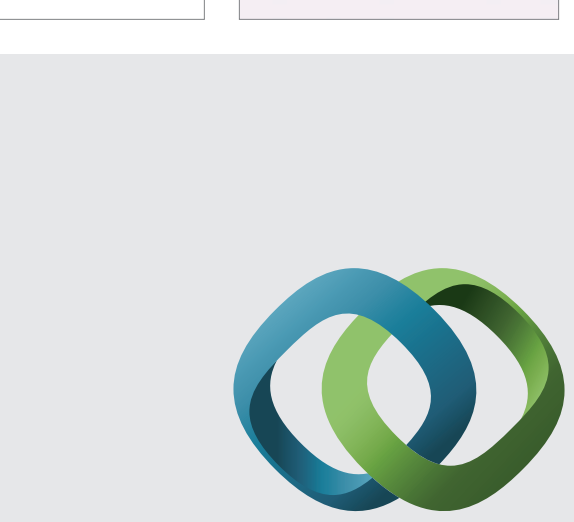

\section{Hindawi}

Submit your manuscripts at

http://www.hindawi.com
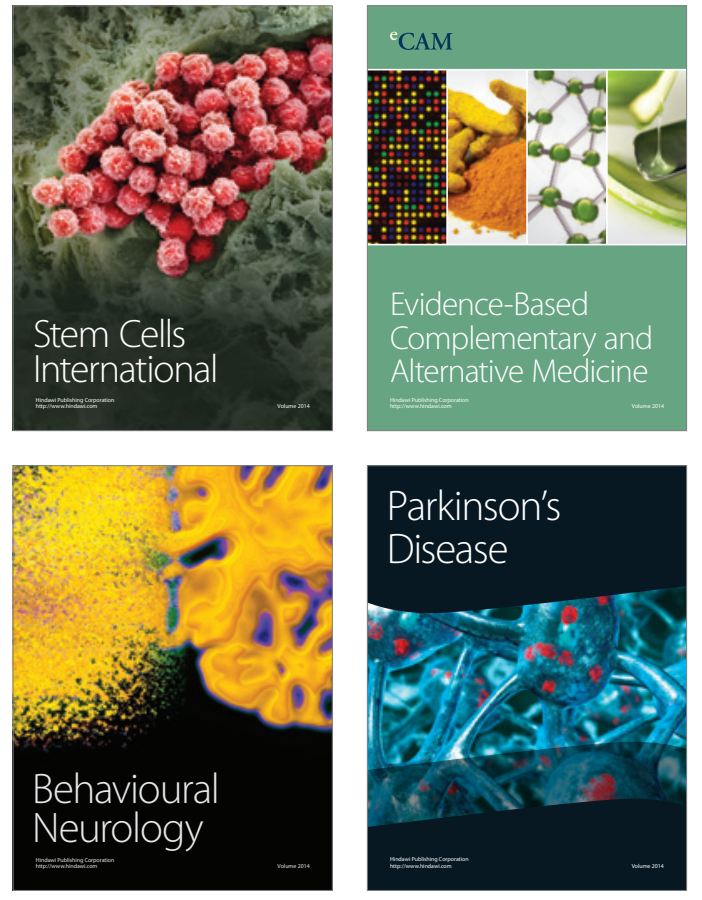
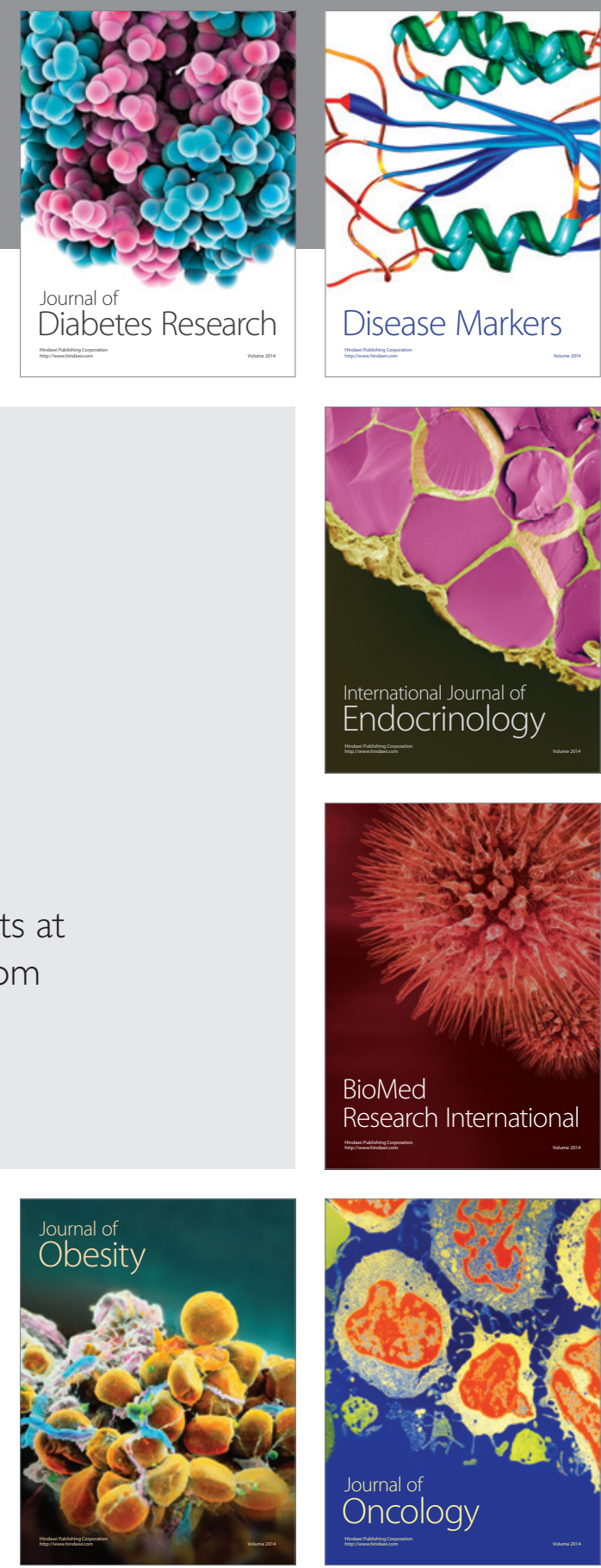

Disease Markers
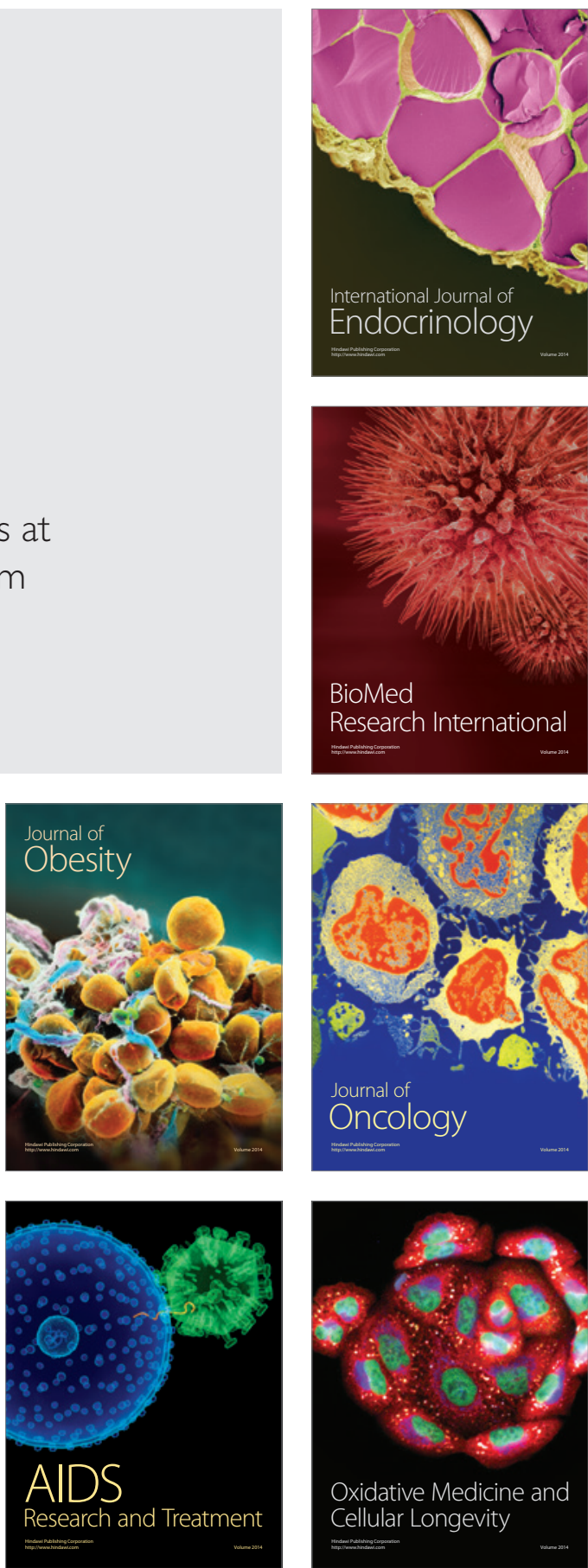